\title{
A RARE CASE OF INTRAOPERATIVE PULMONARY OEDEMA DUE TO HYPOPROTEINAEMIA: A CASE REPORT
}

Shiva P. V1, Suresh Chander D2, Deepraj Singh B³

\section{HOW TO CITE THIS ARTICLE:}

Shiva P. V, Suresh Chander D, Deepraj Singh B. "A Rare Case of Intraoperative Pulmonary Oedema due to Hypoproteinaemia: A Case Report". Journal of Evolution of Medical and Dental Sciences 2015; Vol. 4, Issue 46, June 08; Page: 8096-8100, DOI: 10.14260/jemds/2015/1173

ABSTRACT: Pulmonary oedema may complicate the perioperative period and the aetiology may be different from non-operative patients. Broadly pulmonary oedema is classified as Cardiogenic ${ }^{1}$ and non-cardiogenic. ${ }^{2}$ There are many different and varied reasons for non cardiogenidc perioperative pulmonary oedema including high altitude, ${ }^{3}$ neurogenic ${ }^{4}$ causes, hypoproteinaemia being one of them. Diagnosis may be difficult during anaesthesia and consequently management may be delayed. A careful preoperative assessment to detect hypoalbumineamia in relevant cases may be necessary to expect a complication of such cause and to take steps to prevent and treat. A case is presented here which presented as Chronic intestinal obstruction with marked nutritional imbalance and anasarca, posted for laprotomy under general anaesthesia. Intraoperatively she developed pulmonary oedema which subsequently was managed successfully.

KEYWORDS: Hypoproteinemia, hypoalbunimaemia, malnutrition, pulmonary oedema.

INTRODUCTION: Marked reductions in the circulating levels of proteins, especially albumin, as a cause of Intraoperative pulmonary oedema that relates to intravascular factors is a known entity. Hypoproteinemia may result from rapid loss of proteins across a compromised glomerular barrier in diseased kidneys, impaired hepatic synthesis of plasma proteins in liver disease, severe malnutrition or protein-losing enteropathy (Which limits the availability of substrate for protein synthesis), or from infusion of intravenous fluids lacking macromolecules. The ensuing reduction in the colloid osmotic pressure gradient, which favours reabsorption in the non-steady state and opposes the hydrostatic pressure gradient that favours filtration, induced by hypoproteinemia can result in a large transcapillary flux of protein-poor fluid into the interstitial spaces.

Hypoproteinemia as a cause of perioperative pulmonary oedema, though rare is one of the cause. The other common non cardiogenic causes under anesthesia being neurogenic pulmonary oedema, negative pressure pulmonary oedema hypoxia and anaphylaxis as a cause are more frequently related to pulmonary oedema.

CASE REPORT: A 69 years old female patient weighing $68 \mathrm{kgs}$. was admitted to the hospital with decreased appetite and loose motions and her history revealed that the patient was confined to bed for the last 6 months. She is a known diabetic, hypertensive and hypothyroid. She was receiving treatment with low mol wt Heparin for her bilateral Deep vein thrombosis of both the lower limbs.

On examination she was found to be moderately built and poorly nourished, she was having generalised oedema (Anasarca); she had severe pallor, Hr 118, BP 130/80mmHg, bilateral pitting pedal oedema was present and there was no cyanosis or clubbing. 
Cardiovascular examination shows both the heart sounds were normal, no murmur. In respiratory system there is bilateral air entry was normal and no adventitious sounds. Abdomen was soft non tender and there was no hepatospleenomegaly.

Routine Investigations: Blood picture showed $\mathrm{Hb} \%$ 9.3, RBC count $3.5 \mathrm{Mil} / \mathrm{cm}$. Urea \& Creatinine, RBS, S. Electrolytes were within normal limits.

Liver function test revealed Bilirubin both direct \& indirect were normal, SGOT/SGPT, alkaline Phosphatase were normal, Total serum Proteins 4gm/dl, Albumin 1.5gm/dl, Globulin 2.5gm/dl, A/G ratio 0.6. PT was 18.0 (normal 11.5-15sec) Control 13, INR 1.5, APTT 46 (normal 28-36) control 32. Two days before surgery after 2 units of blood transfusion her HB $8.8 \mathrm{gm} \%$, urea $29 \mathrm{mg} / \mathrm{dl}$, Serum Creatinine $1.1 \mathrm{mg} / \mathrm{dl}$, total proteins $6.7 \mathrm{G} / \mathrm{dl}$ and Serum Albumin $4.1 \mathrm{G} / \mathrm{dl}$. Thyroid profile T3 $0.2 \mathrm{ng} / \mathrm{ml}, \mathrm{T} 44.5 \mu \mathrm{g} / \mathrm{dL}$, TSH $15.42 \mu \mathrm{IU} / \mathrm{ml}$. Chest X-ray was normal, ECG showed low voltage sinus tachycardia. 2D Echo showed thickened pericardium with mild circumcardiac pericardial effusion and EF 60\% Colonoscopy showed Narrowing at the junction of sigmoid and descending colon.

This patient was posted for laparotomy. Patient was connected to multichannel monitor with ECG, NIBP, HR, and SpO2. She was pre-medicated with $0.2 \mathrm{mg}$ Glycopyrrolate, $4 \mathrm{mg}$ Ondansetron, and $40 \mathrm{mg}$ Pantoprazole, $70 \mathrm{mcg}$ Fentanyl. Induction with $200 \mathrm{mg}$ Thio pentone and intubation facilitated with 30mg Atracurium, patient was maintained with 02/N20/0.4\% Sevoflurane with Bains circuit. Intravenous fluids administered through 18 cannula on left hand includes two units !000 mi of ringers lactate solution and $500 \mathrm{ml}$ dextrose in normal saline run throughout the surgery which lasted for two and half hours.

Abdomen was opened with a large midline incision, grossly dilated Right colon upto splenic flexure found, a circumferential obstructing growth found at the splenic flexture. In view of the grossly dilated right colon and, obstructive lesion, resection done and the proximal colon brought out as end colostomy, distal colon closed as a mucus fistula. Haemostasis secured and abdomen closed.

But during the procedure intraoperatively, patient developed severe pulmonary oedema, $40 \mathrm{mg}$ furosemide was given though the urine output improved, pulmonary oedema persisted. At the end of the procedure we decided to electively ventilate the patient till the pulmonary oedema subsides. Patient was connected to the ventilator with $100 \% 02$, tidal volume 500 (calculated on ideal body weight), respiratory rate 15 per minute, PEEP 5 (PEEP adjusted as not to compromise on blood pressure as it was only 110/70 at that time any slight increase in PEEP was causing hypotension). Nitro-glycerine added to the drip (5\% dextrose as piggyback) and run as low dose $5 \mu \mathrm{g} \mathrm{kg} / \mathrm{hour}$ for venodilatation in the treatment of pulmonary oedema.

Once again we reviewed all the reports and decided to give her $100 \mathrm{ml}$ of $20 \%$ Albumin and at the end of the infusion we noticed the saturation improving and the pulmonary oedema subsided. Her ABG report showed pH 7.39, PCO2 40.7, PO2 185.9, $\mathrm{Na}^{+}$144, $\mathrm{K}^{+} 3.83$. FiO2 were gradually decreased to 45 . After $10 \mathrm{hrs}$ of ventilation, she was connected to the T-piece for $6 \mathrm{hrs}$ and her vitals and SpO2 were normal. One unit of $20 \%$ Albumin was repeated and patient was extubated. During this period her vitals were normal and urine output was $900 \mathrm{ml}$. The postoperative investigation revealed Haemoglobin $8 \mathrm{gm} \%$, serum creatinine 1.1mgs, serum electrolytes normal serum proteins total $6.8 \mathrm{gms} / \mathrm{dl}$, serum albumin 3.7gms, globulin 3.1gms.Urine analysis showed albumin + (Urine analysis was not done preoperatively, renal component of proteinuria was missed preoperatively). 
The patient was kept in the ICU for another $24 \mathrm{hrs}$ and was monitored. Periodic blood sugar estimations were done and Insulin was given appropriately. Thyronorm tablet was powdered and given through the Ryle's tube. The patient did not require any antihypertensive during this period. The patient was shifted to her room and discharged after 4 days with the advice of colostomy care, deep breathing exercises, $100 \mathrm{mcg}$ Thyronorm OD, and antibiotics.

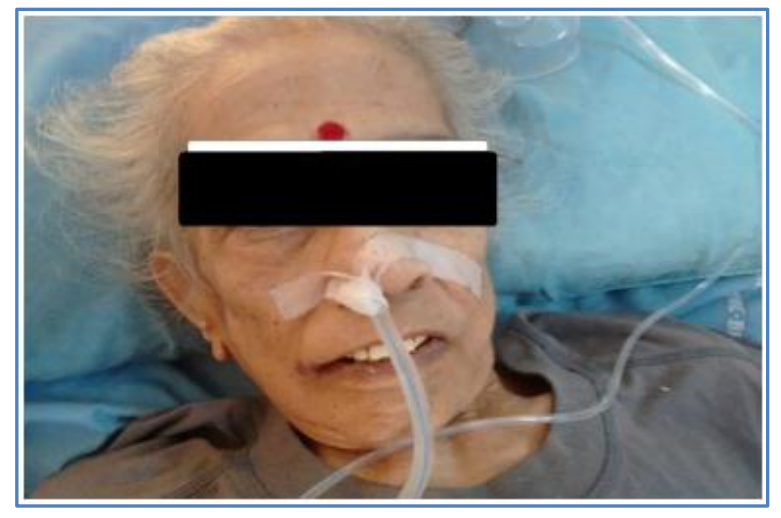

Fig. 1

DISCUSSION: Hypoproteinemia or Hypoalbuminemia is a medical condition where blood levels of albumin are abnormally low. It is a type of hypoproteinemia. Albumin is a major protein in the human body, making up about 55-60\% of total human plasma protein by mass. Many hormones, drugs, and other molecules are mostly bound to albumin in the bloodstream and must be released before becoming biologically active. For example, calcium binds to albumin and hypoalbumineamia leads to an increase in free ionized calcium.

Albumin is synthesized in the liver, and low serum albumin may be indicative of liver failure or diseases such as cirrhosis or chronic hepatitis. Hypoalbuminemia can also present as part of the nephrotic syndrome, in which protein is lost in the urine due to kidney damage. Low albumin levels can be an indicator of chronic malnutrition or protein losing enteropathy.

Hypoalbuminemia may cause generalized oedema (Swelling) via a decrease in oncotic pressure.

The serum albumin level is part of a standard panel of liver function tests. Levels below 3.5 grams per dl are generally considered low.

Nutritional hypoproteinemia is due to severe limitation of protein intake in the diet. In malnutrition, protein levels are decreased in the blood, and in an effort to maintain a balance of concentrations, fluid shifts out of the vessels and causes oedema in tissue spaces.

Malabsorption due to Liver disease can also cause hypoproteinemia by decreasing synthesis of plasma proteins like albumin. In severe sepsis - macrophages are activated in the liver and spleen secrete TNF-alpha into the bloodstream resulting in hypoproteinemia

Decreased serum protein decreases the osmotic pressure of the blood, leading to loss of fluid from the intravascular compartment, or the blood vessels, to the interstitial tissues, resulting in oedema.

Mainstay of management is on improving the total serum proteins levels including albumin levels, which constitutes the major plasma protein in the blood. 
The case presented here is a female patient who was confined to bed for six months with anasarca malnutrition and malabsorbtion syndrome with other co morbid conditions posted for laparotomy as a semi emergency for intestinal obstruction. Vitals recorded before surgery were normal. Routine investigations were within normal limits. ECG showed low voltage sinus tachycardia. 2D Echo showed thickened pericardium with mild circumcardiac pericardial effusion and EF $60 \%$ Induction of anaesthesia and intubation was smooth and without any complication Intraoperative patient developed bilateral crept with oxygen saturation up to $90 \%$, the condition rapidly progressed to frank Pulmonary oedema.

Treatment initiated to control oedema with $100 \%$ oxygen, positive pressure ventilation with PEEP and use of furosemide, nitro-glycerine (Used as venodilator and not as an antihypertensive). After the surgery patient was shifted to intensive care unit and connected to ventilator. Postoperative review detected hypoalbuminaemia which was corrected with two units of $20 \%$ albumin after which patient condition improved. It was finally concluded that hypoalbuinaemia is responsible for intraoperative and postoperative pulmonary oedema. ${ }^{5}$

CONCLUSION: There are many causes of pulmonary oedema during intraoperative period and postoperative ${ }^{5}$ period. In cases where the patient presents with anasarca with malnutrition and malabsorbtion syndrome, or with history suggestive of chronic intestinal pathology it is mandatory for anaesthesiologist in his preoperative assessment insists on serum protein levels suspecting hypoalbuminaemia. Perioperative pulmonary oedema can be prevented by correcting hypoproteinaemia by infusing $20 \%$ albumin as required.

\section{REFERENCES:}

1. DS, et al. Pathophysiology of cardiogenic pulmonary edema. http: //www.uptodate.com/home. Accessed Feb. 26, 2014.

2. Pinto Givertz MM. Non-cardiogenic pulmonary edema. http: //www.uptodate.com/home. Accessed Feb. 26, 2014.

3. Gallagher SA, et al. High altitude pulmonary edema. http: //www.uptodate.com/home. Accessed Feb. 26, 2014.

4. Givertz MM. Neurogenic pulmonary edema. http: //www.uptodate.com/home. Accessed Feb. 26, 2014.

5. Lathan SR, Silverman ME, Thomas BL, Waters WC 4th. Postoperative pulmonary edema. South Med J. 1999 Mar; 92 (3): 313-5. 


\section{AUTHORS:}

1. Shiva P. V.

2. Suresh Chander D.

3. Deepraj Singh B.

\section{PARTICULARS OF CONTRIBUTORS:}

1. Associate Professor, Department of Anaesthesiology, Government Medical College, Nizamabad, Telangana.

2. Associate Professor, Department of Anaesthesiology, Gandhi Medical College, Hyderabad.

FINANCIAL OR OTHER COMPETING INTERESTS: None
3. Professor, Department of Anaesthesiology, Government ENT Hospital Osmania Medical College, Hyderabad.

\section{NAME ADDRESS EMAIL ID OF THE CORRESPONDING AUTHOR:}

Dr. Deepraj Singh B, 1-7-145/15, Opp. Usha Mayuri Theatre, Musheerabad, Hyderabad-500020,

Telangana.

E-mail: drdeepraj@gmail.com

Date of Submission: 19/05/2015. Date of Peer Review: 20/05/2015. Date of Acceptance: 30/05/2015. Date of Publishing: 08/06/2015. 